\title{
A Framework to Assess the Seismic Resilience of Urban Hospitals
}

\author{
Peng Yu, ${ }^{1,2}$ Weiping Wen $\mathbb{D}^{1,2}$ Duofa Ji, ${ }^{1,2}$ Changhai Zhai, ${ }^{1,2}$ and Lili Xie ${ }^{1,3}$ \\ ${ }^{1}$ Key Lab of Structures Dynamic Behavior and Control of the Ministry of Education, Harbin Institute of Technology, \\ Harbin 150090, China \\ ${ }^{2}$ Key Lab of Smart Prevention and Mitigation of Civil Engineering Disasters of the Ministry \\ of Industry and Information Technology, Harbin Institute of Technology, Harbin 150090, China \\ ${ }^{3}$ Institute of Engineering Mechanics, China Earthquake Administration, Harbin 150080, China
}

Correspondence should be addressed to Weiping Wen; wenweiping@hit.edu.cn

Received 22 March 2019; Revised 13 May 2019; Accepted 26 May 2019; Published 11 June 2019

Academic Editor: Jorge Ruiz-García

Copyright (c) 2019 Peng Yu et al. This is an open access article distributed under the Creative Commons Attribution License, which permits unrestricted use, distribution, and reproduction in any medium, provided the original work is properly cited.

The phenomenon of hospital functional interruption has been widely observed in the historical moderate-strong earthquakes, indicating that hospital functionality cannot be well considered in the current seismic design methods. The concept of seismic resilience pays enough attention to postearthquake functionality of buildings, and it is particularly significant for the urban hospitals which play critical role in the urban postearthquake rescue and recovery. This study proposes a framework to assess the seismic resilience of urban hospitals, by incorporating the fault tree analysis (FTA) to consider the interdependency between the damage of nonstructural components and the functionality of medical equipment, as well as the effect of external supplies on the functionality of hospital. The proposed framework is then applied to a case-study hospital, and the results indicate that this hospital needs 1.1 days to resume emergency functionality under REDi repair strategy after design basis earthquake (DBE), while it needs 28.8 days to resume emergency functionality under REDi repair strategy after maximum considered earthquake (MCE). It is found that the seismic resilience of this hospital after MCE cannot meet the community requirements on the recovery time, and necessary measures are needed to improve the seismic resilience. The proposed framework provides the quantitative results of seismic resilience assessment in the preearthquake environment and can further support emergency response planning and seismic retrofits strategies.

\section{Introduction}

Urban hospitals are generally expected to offer timely medical services for the earthquake injuries once the moderate-strong earthquakes strike the city. However, the phenomenon of hospital functional interruption has been widely observed in the historical moderate-strong earthquakes $[1,2]$, indicating that hospital functionality cannot be well considered in the current seismic design methods. The past engineering experience confirmed that the current design codes [3-5] can generally satisfy the requirement on the structural safety. However, nonstructural components damage and functional loss of medical equipment cannot be prevented, and past earthquakes [6-8] have shown that the failure of nonstructural components and medical equipment are the main reason for hospital functional interruption.
Seismic resilience, the ability of a system to maintain preearthquake functionality or recover to a new level, is treated as a promising alternative to deal with the problem of hospital functionality which has been ignored in current seismic codes. Several studies have been performed to study the seismic resilience of hospitals. Yavari et al. [9] defined the hospital performance levels (fully functional, functional, affected functional, and not functional) by utilizing damage data from past earthquakes. The indicators, such as the quality of service and life [10], patient waiting time [11], and functional downtime [12], have been separately adopted to assess the seismic resilience of hospitals. Cimellaro et al. [13] proposed a fast methodology for disaster resilience quantification where factor analysis was used to identify representative factors from varieties of dimensions. Iuliis et al. [14] proposed an interesting method to evaluate the downtime of building structures from three parts (actual 
damage, irrational delays, and utilities disruption) by introducing the fuzzy logic, which are expected to increase the accuracy of resilience evaluation. Monti and Nuti [15] used logical schemes to describe the complex hospital organization and presented a reliability-based procedure to assess the failure probability of hospital services after a seismic event, paying no attention on the recovery process. Bruneau et al. [16] proposed a hospital resilience quantification framework by incorporating the physical performance and hospital functionality. Pan American Health Organization (PAHO) [17] gave a hospital safety guide in the form of checklists and scoring system which aims to quickly determine the interventions that can improve its seismic safety. Fault tree analysis (FTA) is a kind of method for analysing complex systems reliability and safety [18], and it has been applied to the building system failure analysis $[19,20]$. Jacques et al. [21] analysed the functionality of critical clinical and support services by FTA where fault trees were established based on three main factors (staff, structure, and stuff), but the damage data (e.g., utility loss and its duration) from seismic surveys are needed in their method.

In the postearthquake environment, the functionality of medical equipment is greatly affected by the damage extent of nonstructural components. The interdependency between the damage of nonstructural components and the functionality of medical equipment, which has been generally ignored in the previous studies, is significant for the seismic resilience assessment of hospitals. Besides, the external supplies also have an obvious effect on the functionality of hospital, and the situation of external supplies needs to be included in the seismic resilience assessment of hospitals.

In light of the above discussions, a framework for the assessment of the seismic resilience of hospitals is firstly proposed. The fault tree analysis (FTA) is used in this framework to consider the interdependency between the damage of nonstructural components and the functionality of medical equipment, as well as the effect of external supplies on the functionality of hospitals. The different repair strategies, i.e., series, parallel, and Resilience-based Earthquake Design Initiative (REDi) methods [22], are also included in this framework. Finally, the proposed framework is applied to a case-study hospital, and the quantitative assessment results on the seismic resilience are obtained. Innovative building damage assessment methods [23] and retrofit strategies [24] provide lots of alternatives which can be used to improve seismic resilience of hospitals. The proposed framework can further support the assessment and choice of emergency response planning and seismic retrofits strategies.

\section{Resilience Assessment Framework}

Based on earthquake observations, PAHO [17] recognized the importance of hospital safety and put forward the following safety objectives: life safety, investment protection, and functional protection. These objectives aim to ensure that hospitals not only remain standing but hold functionality. By considering the safety objectives proposed by
PAHO, the following indicators are used in the framework: damage state, casualties, economic loss, and availabilities of medical services. In order to reflect the critical role of emergency functionality in the treatment of earthquakeinduced casualties, hospital services are divided into full and emergency. Full means that all components in hospitals are undamaged and hospitals can provide routine and emergency services. Emergency indicates that parts of services are interrupted, but emergency service remains operational. The other two functionality levels are life safety and none. Life safety means that the hospital has lost its capacity of providing medical service, but the main structure would not experience the damage that threat people's life. None indicates that the main structure of the hospital has experienced severe damage or even collapse. Table 1 summarizes the four levels of functionality for hospitals and the corresponding definition. The functionality levels are ranked in the order of implementation difficulty: full, emergency, life safety, and none.

This framework has five main blocks: the earthquake selection, the physical response, the loss analysis, functionality evaluation, and resilience assessment. The response of structure, in terms of maximum interstory displacement ratio (MIDR) and peak floor acceleration (PFA) are obtained by dynamic time history analysis, enable the fragility analysis of structural, nonstructural components, and medical equipment in hospitals. FEMA P58 [25-27] provide a rich component fragility function database for structural and nonstructural components; however, the functionality of medical equipment and external supplies need to be added. The economic loss and the number of casualties are estimated according to the damage states of all components in hospitals. The estimation of functionality level is operated before repair work (if needed) by the estimation rules mentioned above and repeated until the repair work finishes (i.e., updating the functionality level when the repair work progresses). FTA is adopted in this framework to consider the effect of interdependencies on emergency functionality failure. Meanwhile, the selection of repair strategy, such as parallel repair strategy, serial repair strategy, and REDi methods, has an important effect on the recovery phase. Thus, these three repair strategies are also included, and the quantitative effects can be observed in the following case study. Finally, the functionality curve $Q(t)$ is used in the in this framework. Assessment of the resilience of hospitals in future earthquakes inherently entails significant uncertainties. The resilience of hospitals depends on a number of factors which include the intensity of ground shaking, the response of structures, the vulnerability of components to damage, etc. In the framework, Monte Carlo simulation method is used to consider the uncertainties related to those factors.

Figure 1 shows the details and flow chart for the proposed framework. The details on the functionality evaluation (i.e., step of estimating functionality level in Figure 1) are specially explained here. After the physical responses (e.g., damage state of components and medical equipment), the results of loss analysis (e.g., casualties) are obtained. If components and medical equipment are not damaged, the 
TABLE 1: Four levels of functionality and the corresponding definition.

\begin{tabular}{lc}
\hline Functionality & Definition \\
\hline Full & No damage \\
Emergency & Emergency service keeps operational \\
Life safety & Emergency functionality stops \\
None & but no casualties occur \\
\hline
\end{tabular}

functionality of hospital would be in the Full level. Once some components or medical equipment are damaged, then FTA is used to analyse whether the hospital can provide the emergency medical service. If not, the rest two levels will be determined by the casualties.

The framework ends with the computed resilience level, and the resilience index [28] adopted herein is expressed as

$$
R=\int_{t_{O E}}^{t_{O E}+T_{L C}} \frac{Q(t)}{T_{L C} d t}
$$

$T_{L C}$ is the control time interested and $T_{O E}$ is the time when the event happens.

\section{Case Study}

3.1. Hospital Description. The hospital used in this study is a five-story reinforced concrete frame building which is $68 \mathrm{~m}$ long, $45 \mathrm{~m}$ wide, and $18.9 \mathrm{~m}$ high (Figure 2). Figure 3 illustrates the plan of the first and fifth floor and shows the location of critical departments in emergency service. The reinforced concrete frames are designed based on Chinese seismic design code [5]. The seismic fortification intensity of this building is seven, and soil class is II.

For nonlinear dynamic analysis of the hospital, fourteen ground motion records were selected from the PEER ground motion database with the following criteria: (a) the moment magnitude $M_{\mathrm{w}}$ of the seismic events is above 6.0; (b) the average shear wave velocity of the upper $30 \mathrm{~m}$ soil Vs30 varies from $260 \mathrm{~m} / \mathrm{s}$ to $510 \mathrm{~m} / \mathrm{s}$; and (c) the mean acceleration response spectra of selected ground motions match the seismic design spectra of DBE level in Chinese seismic design code [5]. The comparison between the response spectra of selection records and the design spectra is shown in Figure 4, and the good agreement can be observed between them.

Nonlinear time history analysis is performed on threedimensional frames (Figure 5) by SAP2000 [29]. Beams and columns are modelled using frame elements, and the slabs are modelled as rigid diaphragms. Uniaxial moment plastic hinges are assigned at both ends of the beams, and $\mathrm{P}-\mathrm{M}-\mathrm{M}$ interaction hinges are assigned at the bottom of columns. P-delta effect is considered in the analysis. MIDR and PFA are used in this study to quantify the damage of structural components, nonstructural components, and medical equipment. Figure 6 shows the mean MIDR of this building under SLE (service level earthquake), DBE, and MCE. Figure 7 presents the mean PFA of this building under the above intensity levels. The results in Figure 6 indicate that this building meets the
MIDR requirements (i.e., MIDR $<1 / 50$ ) of reinforcement concrete frames in Chinese seismic design code for the collapse prevention.

The logic scheme of the hospital functionality is shown in Figure 8 to illustrate the detailed architecture of hospital medical service. Resuscitation room, radiology department, supply room, oxygen room, and distribution room are located on the first floor. The red arrows in Figure 8 indicate the patient's transfer route from the rescue room to ward. Two elevators and five stairs ensure access to ORs. Two external power grids (black arrows) provide power for the hospital, and no backup generator is equipped here. The emergency service depends on four subsystems: building and medical system, supply system, gas system, and electric system. Hospitals usually set up multiple departments or rooms with the same function to work together in order to expand their treatment capacity (e.g., two operating rooms are set up on the fifth floor in the case study hospital). The interdependencies and redundancies of hospital systems should be considered comprehensively in the estimation of hospital functionality.

FTA is a kind of method to analyse the reliability and safety of complex systems based on the logical combination of a series events. The failure of emergency function is firstly selected as top event of fault tree. Then, intermediate events and basic events are determined by the causal link from top to bottom. The intermediate events are chosen as critical departments in emergency functionality. The fault tree of emergency service is created in collaboration with hospital managers (Figure 9). Rooms or medical equipment with the same functions are connected with AND logic gates to critical departments or rooms in which the redundancy can be taken into account. The basic events, shown as circles, are selected as the damages to critical medical equipment, nonstructural components damage, and loss of external power supply which can be simulated or estimated in preearthquake resilience assessment. The detailed information of all basic events is summarized in Table 2. The interdependencies between damage of nonstructural components and medical equipment are considered here. For example, some sophisticated medical equipment (CT and DR) and medical rooms have special requirements on temperature, humidity, dust, etc. The damage of architecture nonstructural components (e.g., partition wall and pipeline) and interruption of power supply will lead to the interruption of equipment and emergency functionality.

3.2. Functionality Analysis. The fragility functions for nonstructural components are taken from FEMA P-58 [27], and those of medical equipments are assumed to be the same as those of electrical equipments due to the lack of data. The fragilities and consequence functions of basic events in fault tree are listed in Table 2. The failure probability and repair time of external electric grids under different seismic hazards are also assumed in Table 3 for the same reason.

Nonstructural components generally have several damage states, and the corresponding consequence 


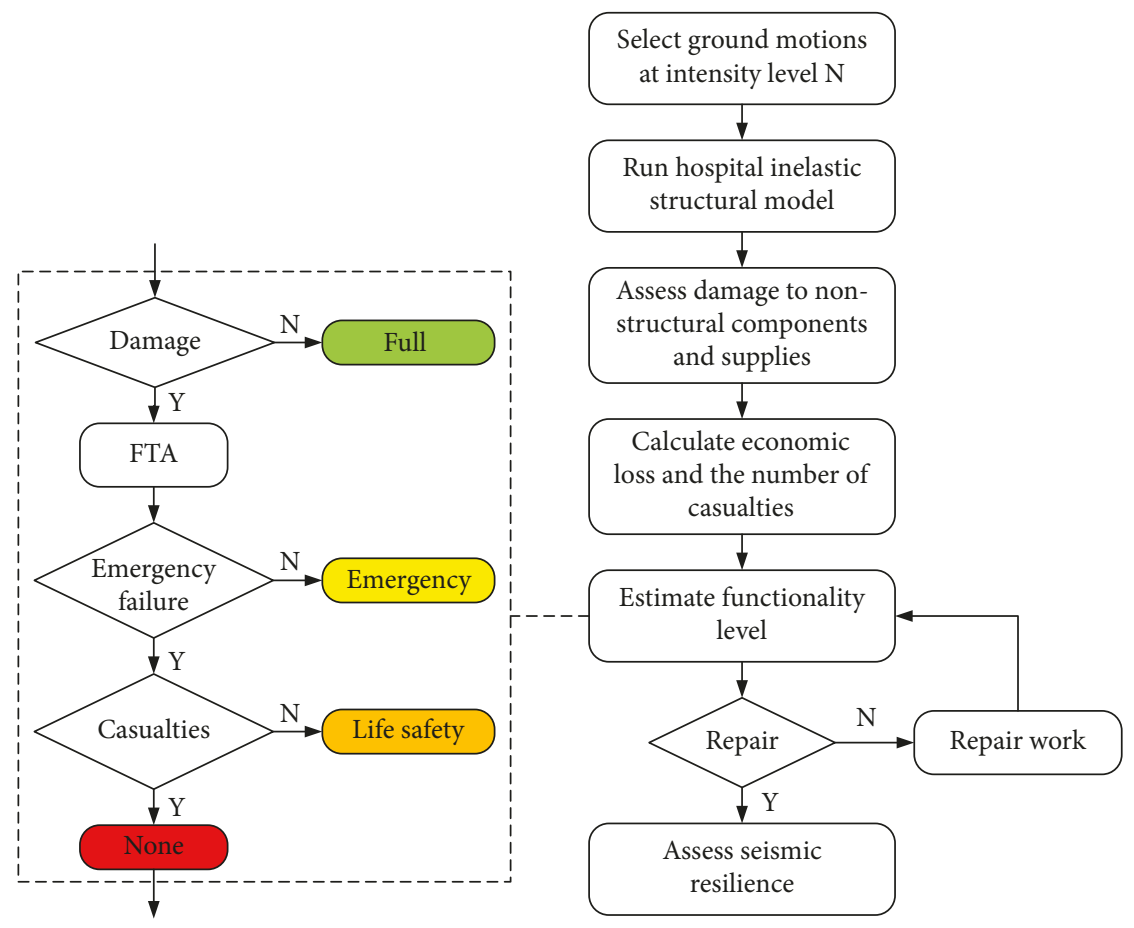

FIGURE 1: Seismic resilience assessment framework of a hospital.

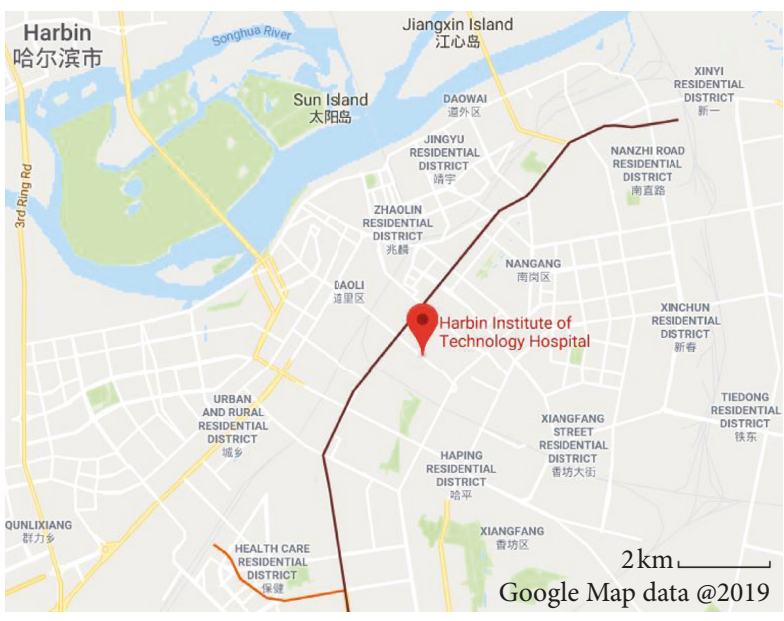

(a)

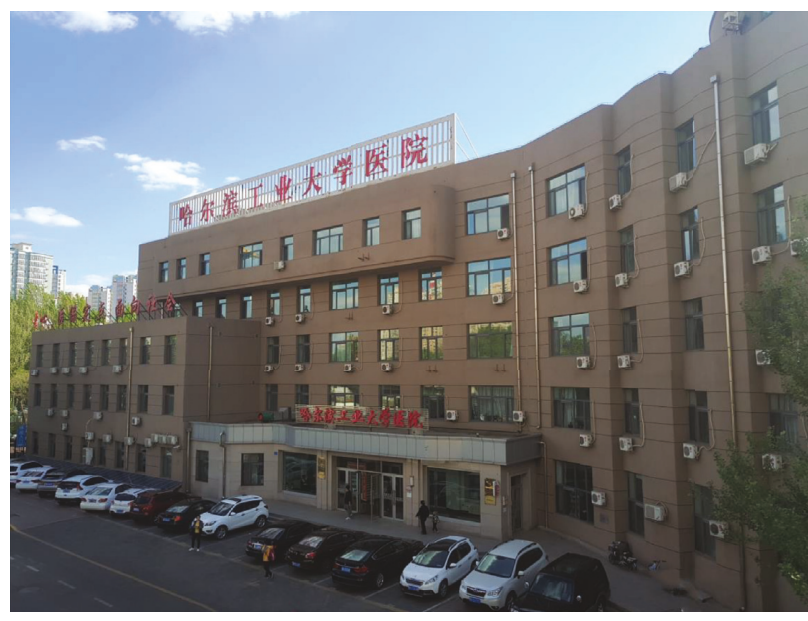

(b)

FIgure 2: The location and exterior of the case study hospital.

functions are different. When using FTA to evaluate the emergency functionality, it is necessary to understand the operation conditions of medical equipment and select the allowable damage states of nonstructural components. For example, CT has strict requirements on air temperature and cleanliness during operation, and the dust generated by partition cracks may cause the CT to run out. So the allowable damage state of partition should be the crack state (i.e., lowest damage state of the partition). For the components that have several damage states, the consequence functions (e.g., repair time) need to be referred to FEMA P-58, and they are not listed in Table 2 for the succinctness.
Performance Assessment Calculation Tool (PACT) [27] is used to calculate the repair cost and repair time under parallel and serial repair strategies. The repair cost is a concerned indicator for hospital managers. Figure 10 shows the median repair cost for the three intensities. At levels of DBE and MCE, the total cost of repair is several magnitudes higher than that at SLE. Probability that the emergency functionality of hospital can keep operational after earthquakes is shown in Figure 11. The emergency functionality is very likely to be continuous under SLE, but the probability reduces to $38.4 \%$ under DBE. After MCE, the emergency functionality will be interrupted entirely. The loss caused by nonstructural components 


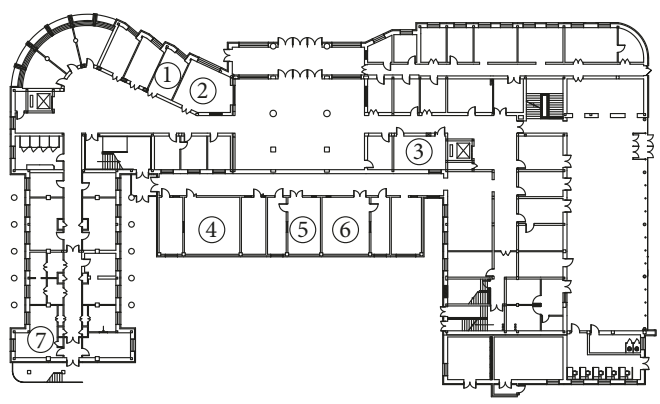

(a)

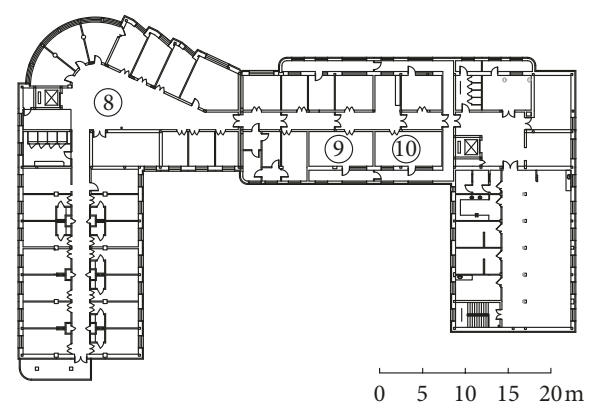

(b)

Figure 3: Hospital building plans. (a) First floor. (b) 5th floor. The rooms numbered from 1 to 9 are resuscitation room, pharmacy, distribution room, magnetic resonance imaging (MRI) room, digital radiography (DR) room, computed tomography (CT) room, supply room, ward, operation room 1 , and operation room 2 , respectively.

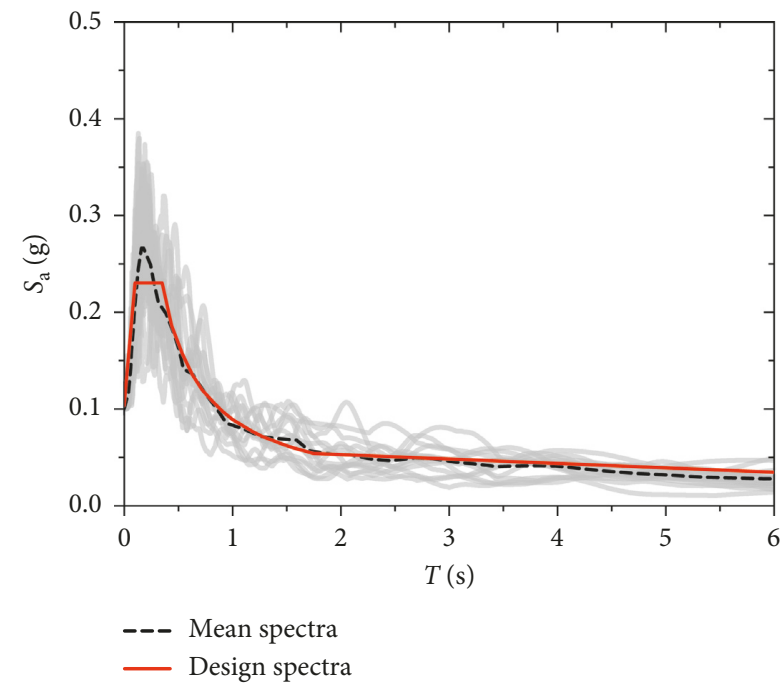

FIGURE 4: Comparison of mean acceleration response and seismic design spectrums.

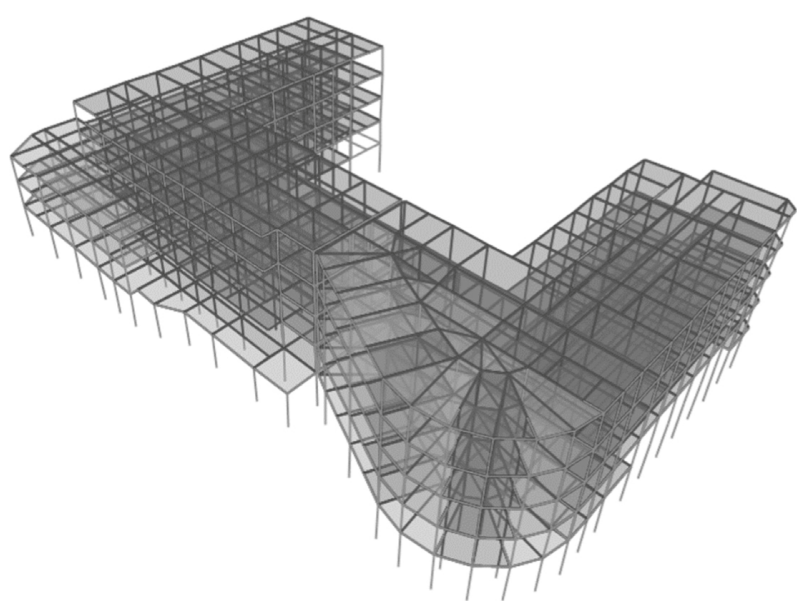

FIGURE 5: Finite element model of case study hospital.

accounts for a large portion of the overall economic loss, confirming again on the importance of nonstructural components.

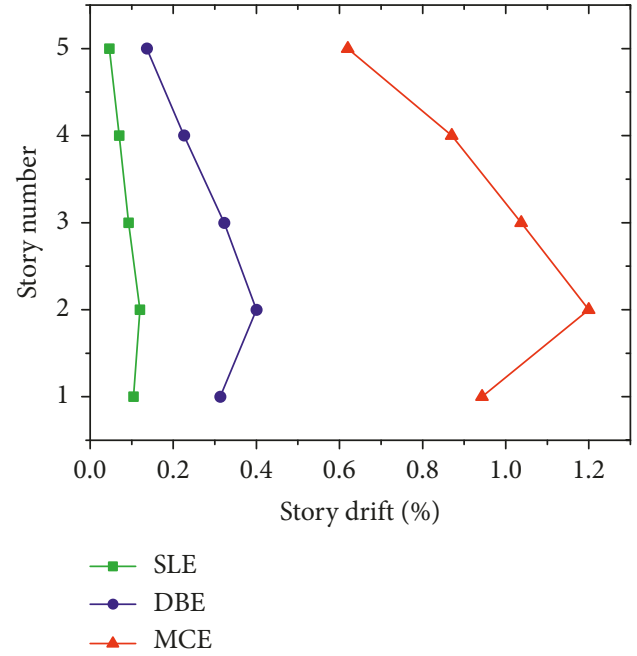

FIGURE 6: Mean MIDR of hospital building under SLE, DBE, and MCE.

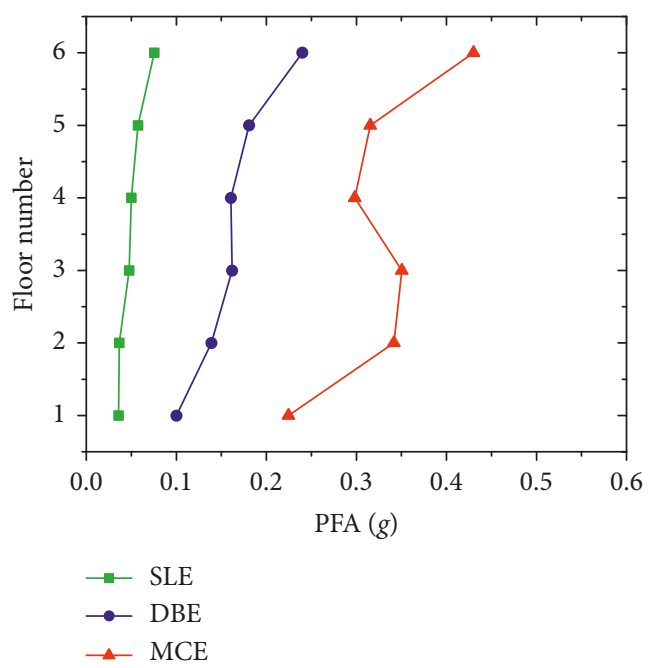

Figure 7: Mean PFA of hospital building under SLE, DBE, and MCE.

3.3. Resilience Analysis. According to the resilience assessment framework in this study, the hospital functionality level needs to be updated with repair processes. The 


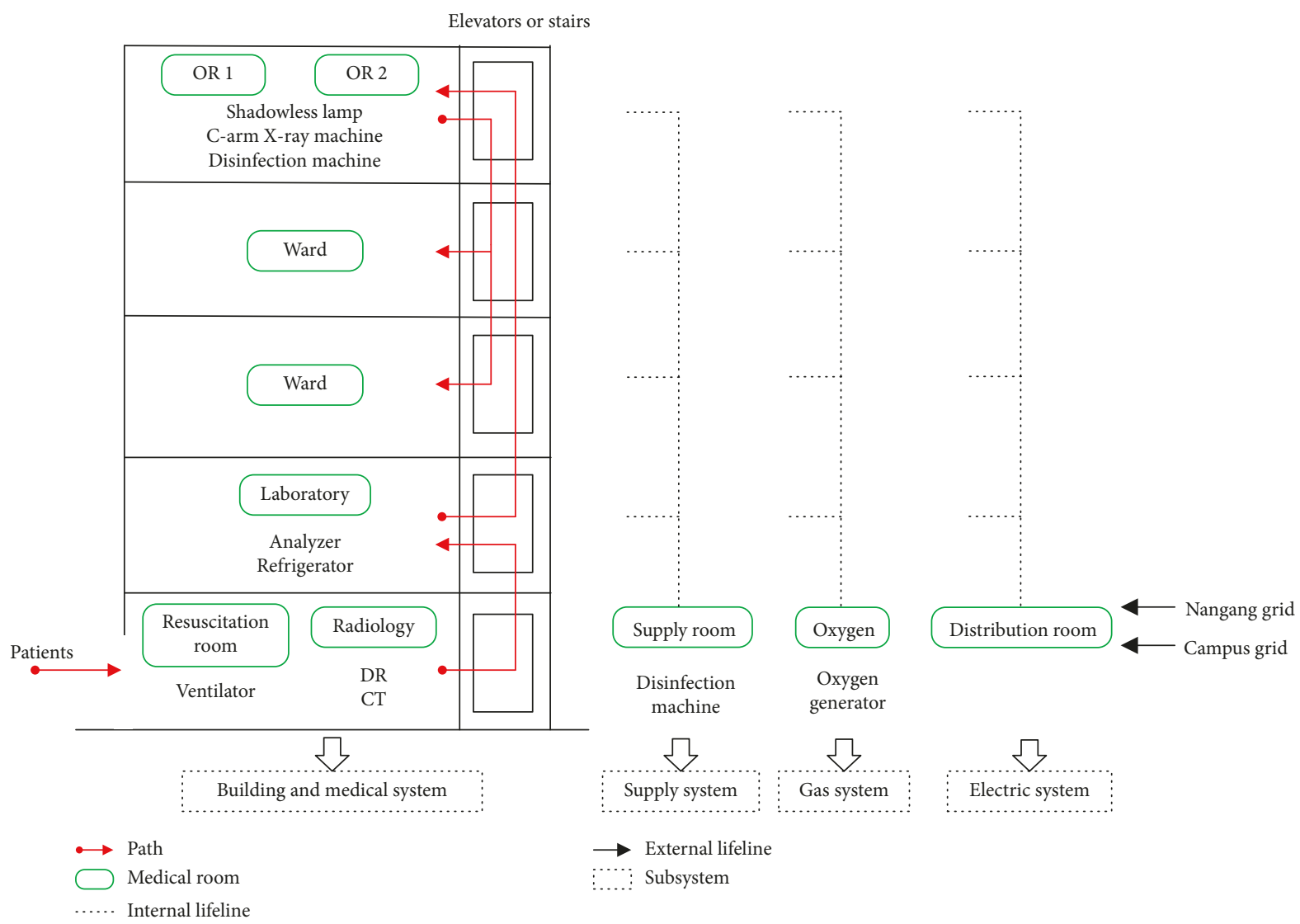

Figure 8: Hospital subsystems and logic scheme of the emergency service.

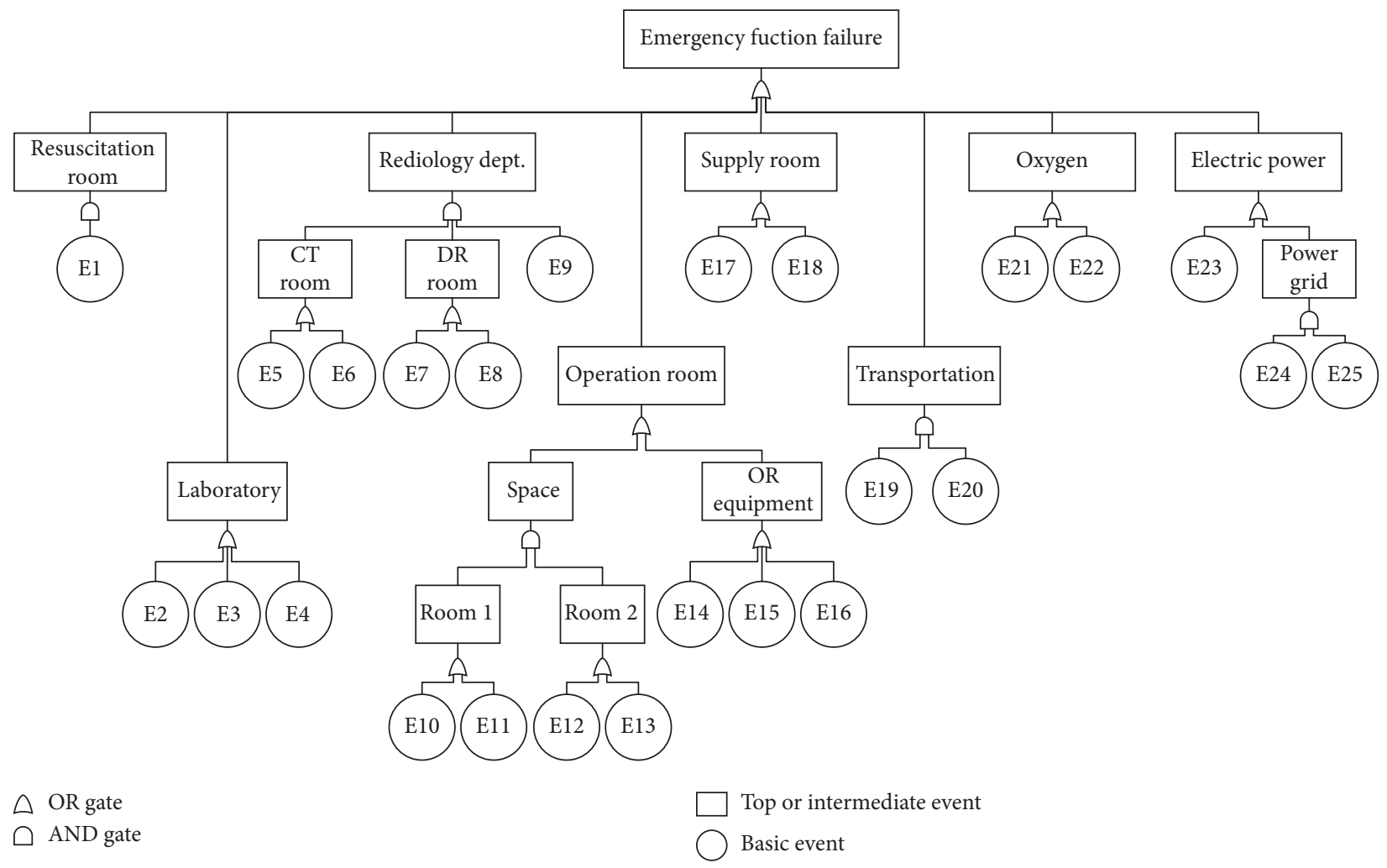

FIgURE 9: The fault tree of hospital emergency function. 
TABle 2: Fragilities of basic events in the fault tree and repair time.

\begin{tabular}{|c|c|c|c|c|}
\hline No. & Event & EDP & (Median, dispersion) & Repair time (days) \\
\hline 1 & Ventilator 1 & PFA & $(1,0.5)$ & $(1,0.5)$ \\
\hline 2 & Refrigerator & PFA & $(1,0.5)$ & $(1,0.5)$ \\
\hline 3 & Blood analyser & PFA & $(0.5,0.5)$ & $(1,0.5)$ \\
\hline 4 & Urine analyser & PFA & $(0.5,0.5)$ & $(1,0.5)$ \\
\hline 5 & $\mathrm{CT}$ & PFA & $(1,0.5)$ & $(0.2,0.5)$ \\
\hline 6 & CT wall & IDR & $(0.005,0.4)$ & \\
\hline 7 & DR & PFA & $(1,0.5)$ & $(0.2,0.5)$ \\
\hline 8 & DR wall & IDR & $(0.004,0.4)$ & \\
\hline 9 & Portable DR & PFA & $(1,0.5)$ & $(1,0.5)$ \\
\hline 10 & Shadow-less lamp 1 & PFA & $(1,0.5)$ & $(1,0.5)$ \\
\hline 11 & Partition in OR1 & IDR & $(0.005,0.4)$ & \\
\hline 12 & Shadow-less lamp 1 & PFA & $(1,0.5)$ & $(1,0.5)$ \\
\hline 13 & Partition in OR2 & IDR & $(0.005,0.4)$ & \\
\hline 14 & Anesthesia machine & PFA & $(1,0.5)$ & $(1,0.5)$ \\
\hline 15 & Ventilator 2 & PFA & $(1,0.5)$ & $(1,0.5)$ \\
\hline 16 & C-arm X-ray machine & PFA & $(1,0.5)$ & $(1,0.5)$ \\
\hline 17 & Disinfection machine & PFA & $(1,0.5)$ & $(1,0.5)$ \\
\hline 18 & Partition 3 & IDR & $(0.005,0.4)$ & \\
\hline 19 & Elevator 1 & PFA & $(0.39,0.45)$ & \\
\hline 20 & Elevator 2 & PFA & $(0.39,0.45)$ & \\
\hline 21 & Oxygen generator & PFA & $(1,0.5)$ & $(1,0.5)$ \\
\hline 22 & Oxygen pipe & PFA & $(1.5,0.4)$ & \\
\hline 23 & Distribution room & PFA & $(0.73,0.45)$ & $(0.6,0.4)$ \\
\hline
\end{tabular}

TAвLe 3: External electric grid (E24 and E25) failure probability and repair time (days).

\begin{tabular}{lcccc}
\hline & Pf (E24) & Repair time (median, dispersion) & Pf (E25) & Repair time (median, dispersion) \\
\hline SLE & 0.1 & $(0.5,0.5)$ & 0.1 & $(2,0.5)$ \\
DBE & 0.2 & $(1,0.5)$ & 0.3 & $(4,0.5)$ \\
MCE & 0.3 & $(2,0.5)$ & 0.4 & $(0.3,4)$ \\
\hline
\end{tabular}

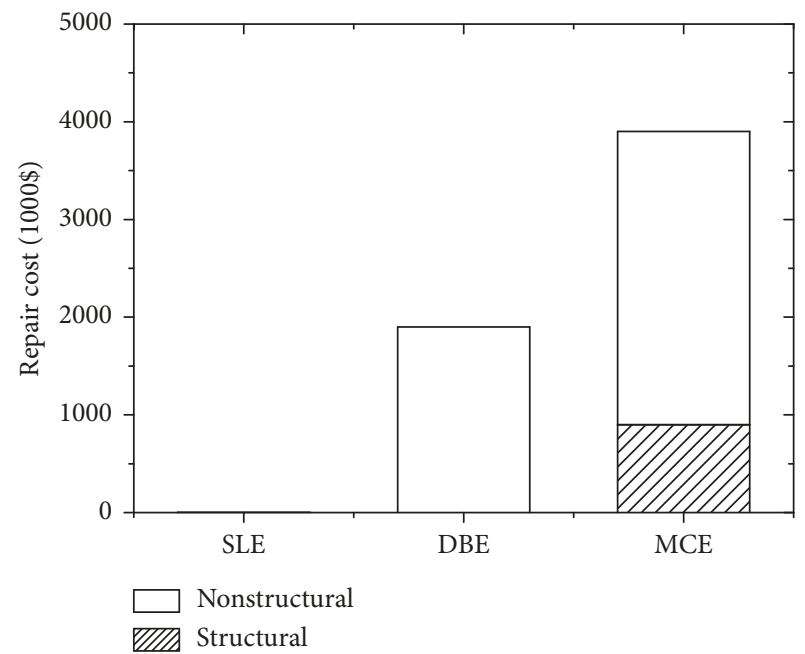

Figure 10: Median repair cost.

recovery curve illustrated in Figure 12 can be plotted along with time. The median functionality is used as the postearthquake hospital functionality, and the $T_{1}$ and $T_{2}$ in curves are equal to median recovery time to higher functionalities, respectively. For comparing the resilience index of a case-study hospital under MCE, DBE, and SLE,

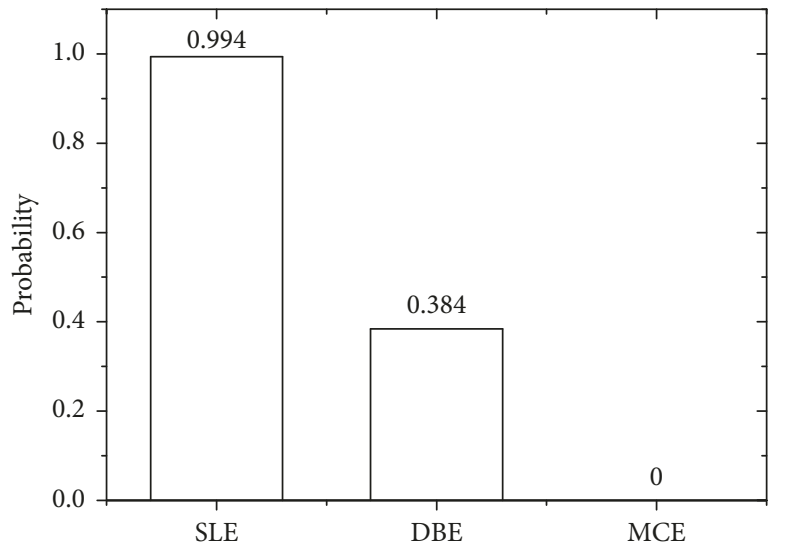

FIGURE 11: Probability that the emergency functionality of hospital can remain operational after earthquakes.

$T_{L C}$ is equal to the longest recovery time under three intensities. Three main repair strategies (parallel, serial, and REDi methods) are considered in the case study. Parallel strategy assumes that repair work is carried out simultaneously at all floors, while serial strategy assumes that repair work is carried out from ground to top floor. Both repair strategies assume that all damaged components are repaired sequentially within one floor. Compare 


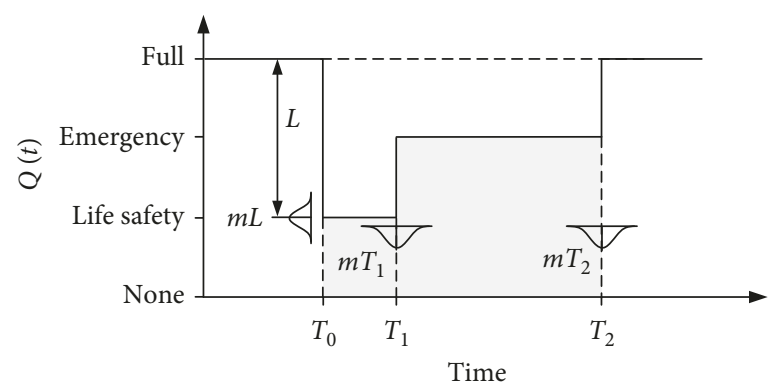

FIGURE 12: Hospital systems functionality curve and earthquake resilience.

to parallel and serial strategies, REDi method makes improvements on the allocation of labor and repair scheme which fits the reality.

The quantification of the four functionality levels (Table 1) is needed, in order to compute the resilience index expressed by equation (1). The values of functionality function $Q$ for four functionality levels (high to low) is $1.0,0.5,0.3$, and 0.0 , by comprehensively considering the suggestions from experts and hospital managers, as well as our engineering experience. Figure 13 shows the recovery curves of hospital for the cases of three different earthquake levels and three different repair strategies.

It can be observed that the SLE has no effect on the emergency functionality, and the hospital also can recover to preearthquake level very quickly. The emergency functionality would be interrupted by the strike of DBE and MCE, but the main building of hospital would be life safety. The case study hospital needs 1.1 days to resume emergency functionality under REDi repair strategy after DBE, while it needs 28.8 days to resume emergency functionality under REDi repair strategy after MCE. It would take 8.2 days and 50 days to recover to the preearthquake level when the hospital is subjected to DBE and MCE, respectively.

The impact of the repair strategy is obvious for the cases of DBE and MCE. Figure 14 presents the recovery curves for different repair strategies when the hospital is subjected to MCE. The recovery curves in parallel and serial strategies provide the lower and upper bound for that in REDi strategy.

When calculating resilience index $R$ by equation (1), $T_{L C}$ is taken as 50 days which equals the final recovery time corresponding to MCE. The results of final recovery time and resilience index under SLE, DBE, and MCE are summarized in Table 4. The resilience index of case study hospital under MCE equals 0.39 which is much lower than that under SLE (0.99) and DBE (0.92).

After earthquakes, the number of injuries and the demand for medical services will change significantly over time. For example, the injuries in the Northbridge earthquake were more frequent than usual, but injury admissions tended to return to normal levels after several days [30]. As seriously injured patients have a narrow window of survival, the hospital functionality (especially the emergency functionality) should be coordinated with the demand of injuries and meet the minimum survival time. According to the analysis of the case study hospital, the recovery time (e.g., 28.8 days for case of MCE) of the emergency functionality is too long to cure numerous injuries. The results indicate that the case study hospital needs to be retrofitted or strengthened to improve its seismic resilience.

\section{Conclusions}

A framework is proposed in this study to assess the seismic resilience of hospital. The fault tree analysis (FTA) is used in this framework to consider the interdependency between the damage of nonstructural components and the functionality of medical equipment, as well as the effect of external supplies on the functionality of hospital. The different repair strategies (i.e., series, parallel, and REDi) are also considered in this framework. Finally, the proposed framework is applied to a case-study hospital, and the main conclusions are as following:

(1) The adoption of FTA in the framework facilitates the consideration of interdependency between the damage of nonstructural components and the functionality of medical equipment, as well as the effect of external supplies on the functionality of hospital, making the framework provide more realistic assessment results on seismic resilience.

(2) The case-study hospital needs 1.1 days to resume emergency functionality under REDi repair strategy after DBE (design basis earthquake), while it needs 28.8 days to resume emergency functionality under REDi repair strategy after MCE (maximum considered earthquake). The seismic resilience of case study hospital after MCE cannot meet the community requirements on the recovery time, and decision-makers need to take necessary measures to improve the seismic resilience.

(3) The repair strategy has clear effects on the recovery time and resilience assessment results, and it should be noted that the quantitative assessment results provided by this framework depend the selection of repair strategy (i.e., series, parallel, and REDi).

The lack of fragility and consequence data of medical equipment and external supplies may influence the 

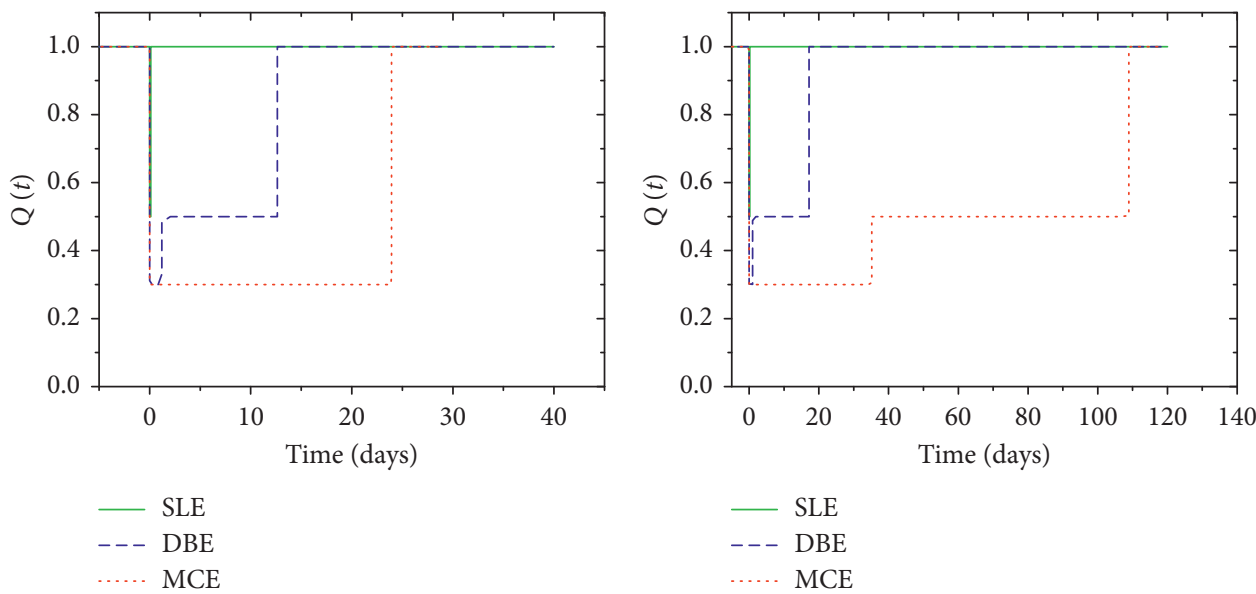

(a)

(b)

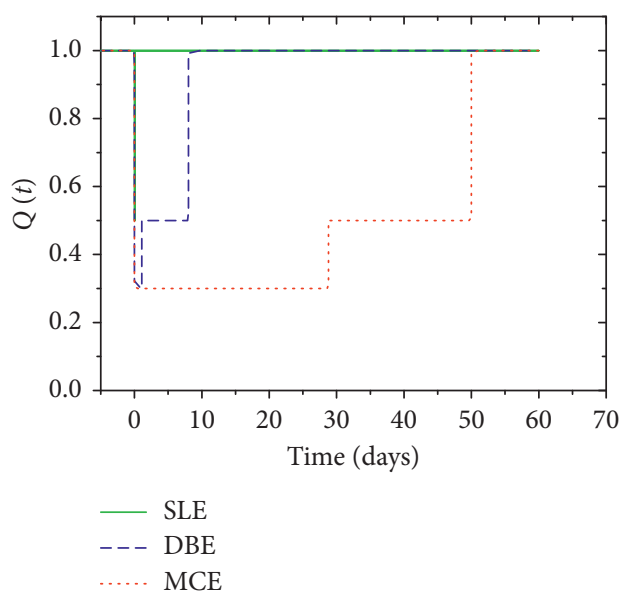

(c)

FIGURE 13: Recovery curves under (a) recovery curves under the parallel strategy, (b) recovery curves under the serial strategy, and (c) recovery curves under REDi strategy.

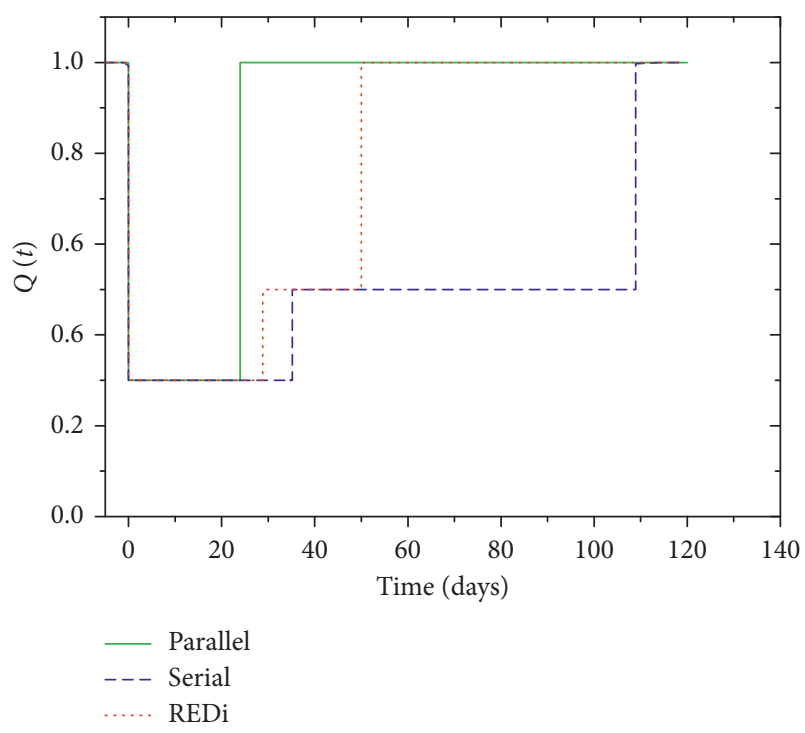

Figure 14: Recovery curves under MCE by different repair strategies.
TABLE 4: Resilience index and recovery time of case study hospital under three intensity levels.

\begin{tabular}{lcc}
\hline Earthquake intensity & Recovery time (days) & $R$ \\
\hline SLE & 0.1 & 0.99 \\
DBE & 8.2 & 0.92 \\
MCE & 50 & 0.39 \\
\hline
\end{tabular}

quantitative results but would not affect the flexibility and usage of the proposed framework. However, attention should be paid to the usability of the fault tree proposed in the case study because of differences among hospitals, and a revised fault tree may be needed. The direct extensions of results beyond the case study are not suggested due to the specific seismic hazards and structure type here. Extensive applications of this framework will be completed by the cooperation of experts from different multidisciplinary such as engineers, architects, specialists in hospital equipment, and health-care professionals. The framework provides evaluation criteria for the update 
strategy and can be further applied to other types of critical facilities.

\section{Data Availability}

The ground motions used in this study are deposited in the Pacific Earthquake Engineering Research Centre (PEER) Next Generation Attenuation (NGA) relationships database (http://ngawest2.berkeley.edu/). The software PACT is used to support this study, and it is available at https://www. atcouncil.org/p-58.

\section{Conflicts of Interest}

The authors declare that there are no conflicts of interest regarding the publication of this paper.

\section{Acknowledgments}

The authors want to express their sincere gratitude to Jing Chen, Vice President of Hospital of Harbin Institute of Technology, for her kind help. This investigation is supported by the National Natural Science Foundation of China (nos. 51825801 and 51708161), National Key R\&D Program of China (no. 2017YFC1500604), and China Postdoctoral Science Foundation (no. 2018T110305). These supports are greatly appreciated.

\section{References}

[1] T. D. Kirsch, J. Mitrani-Reiser, R. Bissell et al., "Impact on hospital functions following the 2010 Chilean earthquake," Disaster Medicine and Public Health Preparedness, vol. 4, no. 2, pp. 122-128, 2010.

[2] J. Mitrani-Reiser, M. Mahoney, W. T. Holmes et al., “A functional loss assessment of a hospital system in the bio-bio province," Earthquake Spectra, vol. 28, no. 1, pp. 473-502, 2012.

[3] European Committee for Standardization, Eurocode 8: Design of Structures for Earthquake Resistance-Part 1: General Rules, Seismic Actions and Rules for Buildings, 2004.

[4] American Society of Civil Engineers/Structural Engineering Institute, Minimum Design Loads for Buildings and Other Structures ASCE 7-10, Reston, VA, USA, 2009.

[5] Ministry of Housing and Urban-Rural Development of China, Code for Seismic Design of Buildings GB 50011-2010, Beijing, China, 2016, in Chinese.

[6] N. Achour, M. Miyajima, M. Kitaura, and A. Price, "Earthquake-induced structural and nonstructural damage in hospitals," Earthquake Spectra, vol. 27, no. 3, pp. 617-634, 2011.

[7] G. Santarsiero, L. Di Sarno, S. Giovinazzi et al., "Performance of the healthcare facilities during the 2016-2017 Central Italy seismic sequence," Bulletin of Earthquake Engineering, pp. 1-27, 2018.

[8] R. C. Myrtle, S. F. Masri, R. L. Nigbor, and J. P. Caffrey, "Classification and prioritization of essential systems in hospitals under extreme events," Earthquake Spectra, vol. 21, no. 3, pp. 779-802, 2005.

[9] S. Yavari, S. E. Chang, and K. J. Elwood, "Modeling postearthquake functionality of regional health care facilities," Earthquake Spectra, vol. 26, no. 3, pp. 869-892, 2010.
[10] G. P. Cimellaro, A. M. Reinhorn, and M. Bruneau, "Seismic resilience of a hospital system," Structure and Infrastructure Engineering, vol. 6, no. 1-2, pp. 127-144, 2010.

[11] G. P. Cimellaro, M. Malavisi, and S. Mahin, "Using discrete event simulation models to evaluate resilience of an emergency department," Journal of Earthquake Engineering, vol. 21, no. 2, pp. 203-226, 2017.

[12] P. Favier, A. Poulos, J. A. Vásquez et al., "Seismic risk assessment of an emergency department of a Chilean hospital using a patient-oriented performance model," Earthquake Spectra, 2018, In press.

[13] G. P. Cimellaro, M. Malavisi, and S. Mahin, "Factor analysis to evaluate hospital resilience," ASCE-ASME Journal of Risk and Uncertainty in Engineering Systems, Part A: Civil Engineering, vol. 4, no. 1, article 04018002, 2018.

[14] M. D. Iuliis, O. Kammouh, G. P. Cimellaro, and S. Tesfamariam, "Downtime estimation of building structures using fuzzy logic," International Journal of Disaster Risk Reduction, vol. 34, pp. 196-208, 2019.

[15] G. Monti and C. Nuti, "A procedure for assessing the functional reliability of hospital systems," Structural Safety, vol. 18, no. 4, pp. 277-292, 1996.

[16] M. Bruneau and A. Reinhorn, "Exploring the concept of seismic resilience for acute care facilities," Earthquake Spectra, vol. 23, no. 1, pp. 41-62, 2007.

[17] Pan American Health Organization (PAHO), Hospital Safety Index: Guide for Evaluators, Washington, DC, USA, 2008.

[18] W. S. Lee, D. L. Grosh, F. A. Tillman, and C. H. Lie, "Fault Tree analysis, methods, and applications-a review," IEEE Transactions on Reliability, vol. R-34, no. 3, pp. 194-203, 1985.

[19] S. Youance, M.-J. Nollet, and G. McClure, "Effect of critical sub-system failures on the post-earthquake functionality of buildings: a case study for Montréal hospitals," Canadian Journal of Civil Engineering, vol. 43, no. 10, pp. 929-942, 2016.

[20] K. Porter and K. Ramer, "Estimating earthquake-induced failure probability and downtime of critical facilities," Journal of Business Continuity \& Emergency Planning, vol. 5, no. 4, pp. 352-364, 2012.

[21] C. C. Jacques, J. McIntosh, S. Giovinazzi, T. D. Kirsch, T. Wilson, and J. Mitrani-Reiser, "Resilience of the canterbury hospital system to the 2011 christchurch earthquake," Earthquake Spectra, vol. 30, no. 1, pp. 533-554, 2014.

[22] I. Almufti and M. Willford, REDi ${ }^{\mathrm{TM}}$ Rating System: ResilienceBased Earthquake Design Initiative for the Next Generation of Buildings, Arup, San Francisco, CA, USA, 2013.

[23] G. P. Cimellaro, G. Scura, C. S. Renschler, A. M. Reinhorn, and H. U. Kim, "Rapid building damage assessment system using mobile phone technology," Earthquake Engineering and Engineering Vibration, vol. 13, no. 3, pp. 519-533, 2014.

[24] G. P. Cimellaro and D. Lopez-Garcia, "Algorithm for design of controlled motion of adjacent structures," Structural Control and Health Monitoring, vol. 18, no. 2, pp. 140-148, 2011.

[25] Federal Emergency Management Agency (FEMA), Seismic Performance Assessment of Buildings Volume 1-Methodology, Technical Report FEMA-P58, Washington, DC, USA, 2012.

[26] Federal Emergency Management Agency (FEMA), Seismic Performance Assessment of Buildings Volume 2-Implementation Guide, Technical Report FEMA-P58, Washington, DC, USA, 2012.

[27] Federal Emergency Management Agency (FEMA), Seismic Performance Assessment of Buildings Volume 3-Supporting Electronic Materials and Background, Technical Report FEMA-P58, Washington, DC, USA, 2012. 
[28] G. P. Cimellaro, A. M. Reinhorn, and M. Bruneau, "Framework for analytical quantification of disaster resilience," Engineering Structures, vol. 32, no. 11, pp. 3639-3649, 2010.

[29] CSI (Computers and Structures Inc.), SAP2000 v20 Integrated Finite Element Analysis and Design of Structures, CSI, Berkeley, CA, USA, 2018.

[30] D. L. McArthur, C. Peek-Asa, and J. F. Kraus, "Injury hospitalizations before and after the 1994 Northridge, California earthquake," American Journal of Emergency Medicine, vol. 18, no. 4, pp. 361-366, 2000. 


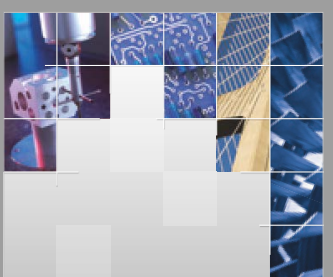

\section{Enfincering}
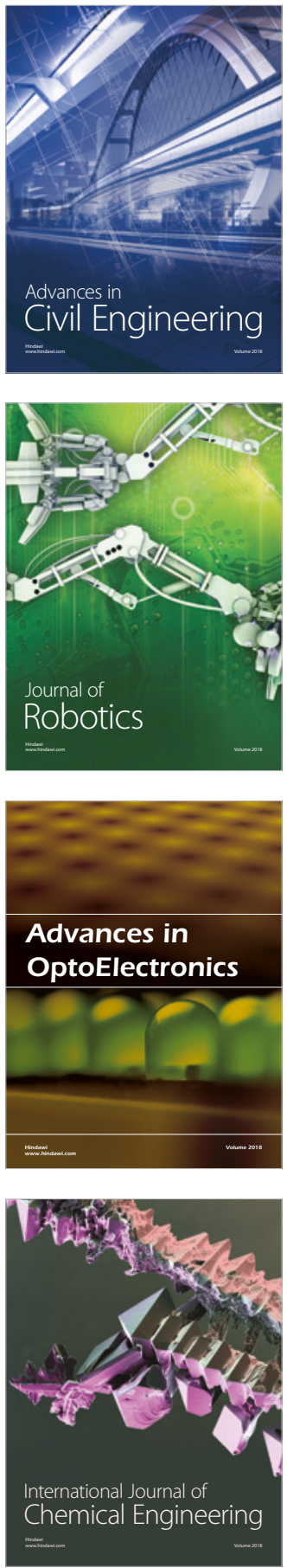

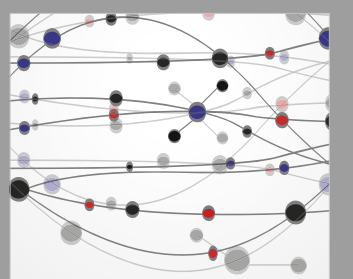

\section{Rotating \\ Machinery}

The Scientific World Journal

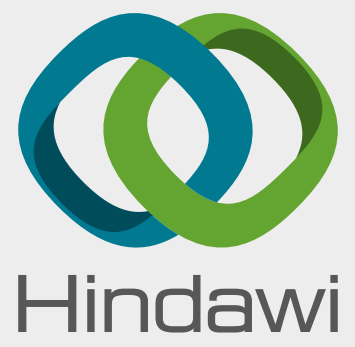

Submit your manuscripts at

www.hindawi.com
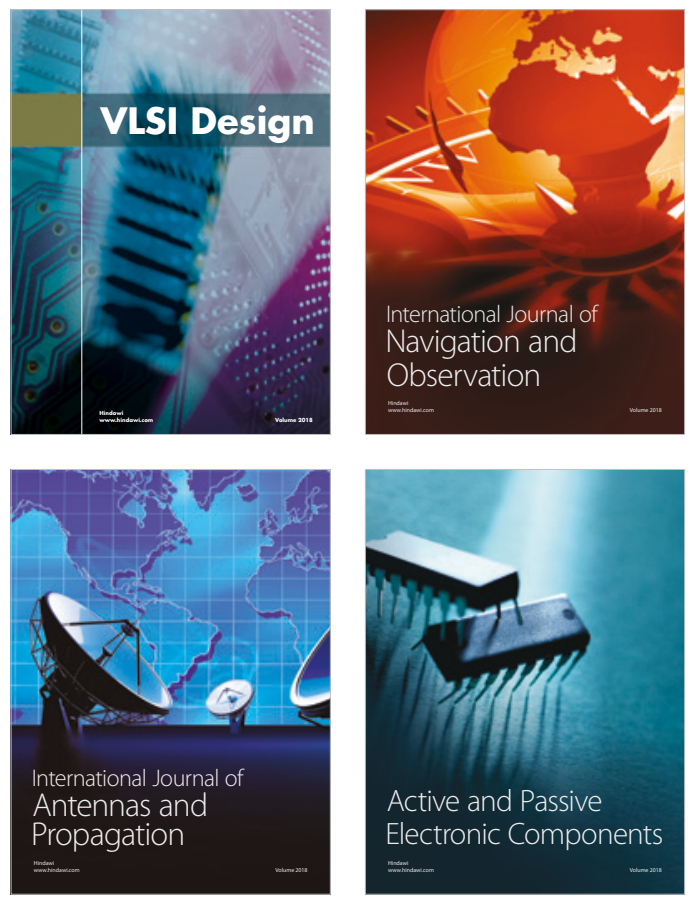
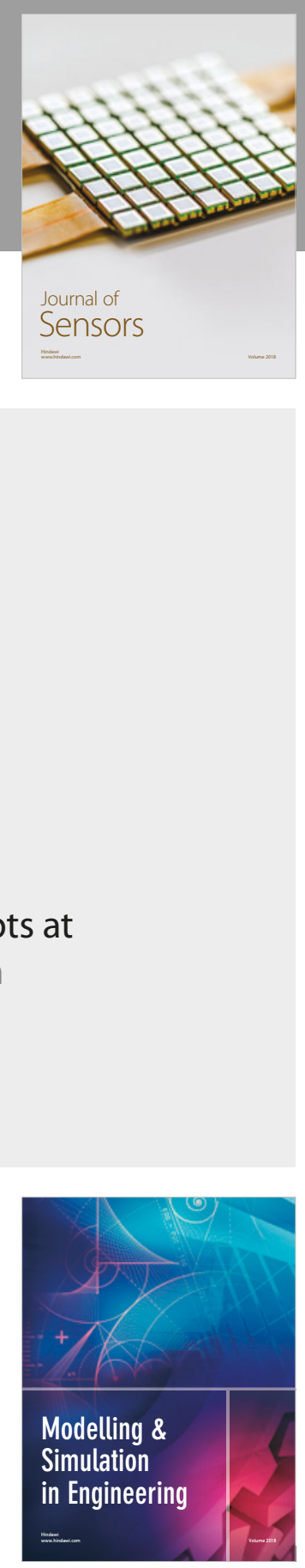

\section{Advances \\ Multimedia}
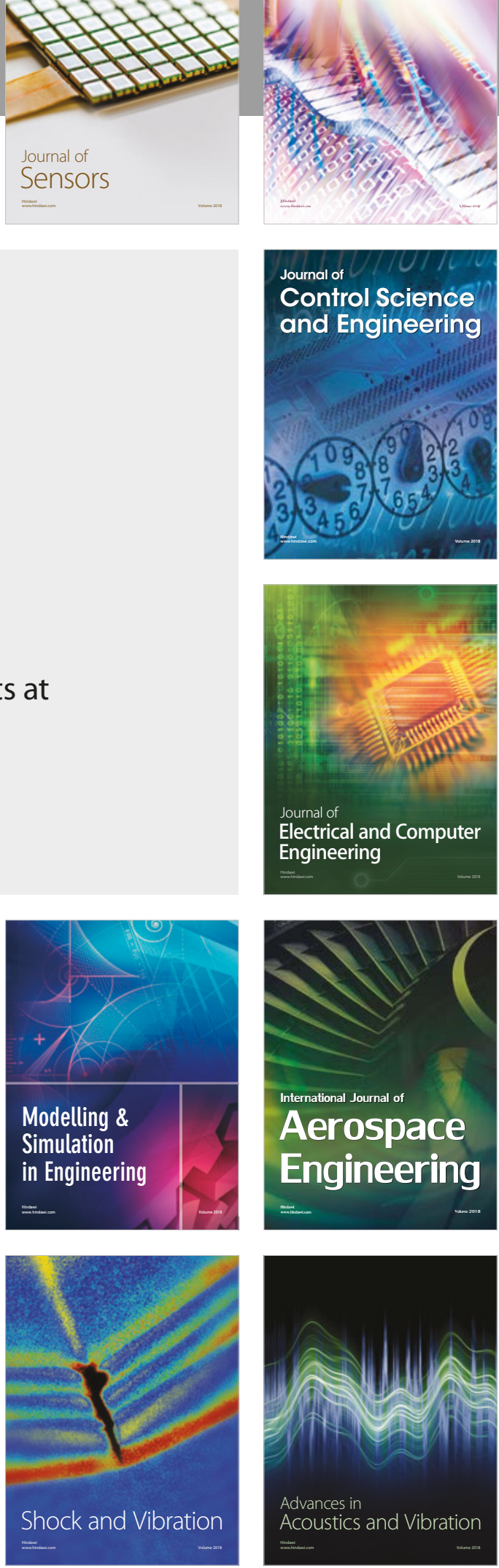